$$
\text { ¿ B Research Square }
$$

\title{
Physicochemical Quality of Metformin Hydrochloride tablet Brands available in Jimma Town, South west, Ethiopia
}

Yimer Mekonnen ( $\nabla$ yimermekonnen30@yahoo.com )

Jimma University

Anbessa Bekele

Jimma University

Sultan Suleiman

Jimma University

Belachew Umeta Chali

Jimma University

\section{Research Article}

Keywords: Metformin hydrochloride, quality, Jimma, Ethiopia

Posted Date: April 6th, 2021

DOI: https://doi.org/10.21203/rs.3.rs-352338/v1

License: (9) (1) This work is licensed under a Creative Commons Attribution 4.0 International License. Read Full License 


\section{Abstract}

Introduction: Metformin hydrochloride, classified under the class of biguanide, is an oral anti-diabetic agent used in type 2 diabetes mellitus patients. According to the biopharmaceutical classification system, metformin is classified as a Class III drug. This study aims to compare the quality of metformin hydrochloride $500 \mathrm{mg}$ tablets available in Jimma town.

Methods: The physical characteristic, packaging and labeling information of samples were evaluated according to the WHO guideline. In-vitro tests such as weight variation, friability, dissolution rate, and assay were performed on six brands of metformin hydrochloride tablets available in Jimma town following method outlined in USP. Experimental data were analyzed using SPSS- 20 and one-way ANOVA. To compare the dissolution profiles of the generic products with innovator product, a model-independent approach, similarity factor $\left(\mathrm{f}_{2}\right)$, difference factor $\left(\mathrm{f}_{1}\right)$ and dissolution efficiency (DE) were used.

Results: All the tested brands were in line with the WHO specifications for physical characteristics, packaging and labeling of pharmaceuticals. Insumet had percent weight deviation more than $5 \%$ and failed to comply with the USP specification for uniformity of weight. Statistically, all brands had significant difference in their mean weight variation $(P<0.001)$. The assay results range from $95.21 \%$ to $99.61 \%$ showing that all the brands met the USP requirement. Moreover, a single point dissolution test results of the brands ranged from $85.4 \%$ to $96.7 \%$ showing compliance to USP specification.

Conclusion: No brand showed any sign of counterfeit and only Insumet failed to comply with the USP specification for weight variation test. All brands complied with the United States Pharmacopeia specification for the friability, assay and single point dissolution test. Furthermore, the model-independent approach and dissolution efficiency revealed that all the brands were interchangeable with the comparator product.

\section{Introduction}

Diabetes mellitus (DM) is a metabolic disorder characterized by a persistently elevated blood glucose associated with absent or inadequate pancreatic insulin secretion, with or without concurrent impairment of insulin action. ${ }^{1}$ There are two main types of diabetes, type 1 diabetes mellitus and type 2 diabetes mellitus. Type 2 diabetes mellitus is the most common form of diabetes and a rapidly growing health concern in both developed and developing nations. ${ }^{2,3}$ It accounts for $90-95 \%$ of all person with diabetes and is expected to increase to 439 million by $2030 .{ }^{4,5}$ Among the treatment options existing, Metformin hydrochloride is the most widely used oral medication to treat type 2 diabetes worldwide. ${ }^{3}$

Metformin hydrochloride, an oral anti-diabetic agent, acts by lowering both basal and postprandial plasma glucose. Other anti-diabetic agent such as sulfonylurea may induce hypoglycemia but metformin hydrochloride does not cause hypoglycemia at any reasonable dose and usually called antihyperglycemic agent. Metformin hydrochloride work as an insulin sensitizer; allowing the body in utilizing insulin and it's classified under biguanide class. ${ }^{6-8}$

Metformin hydrochloride ( $\mathrm{N}, \mathrm{N}$-dimethyl-imido-dicarbonimidic diamide hydrochloride) is small basic compound which has molecular weight of 129 Da and ionized at physiological PH. ${ }^{9}$ Even though metformin is hydrophilic base chemically, it's usually present in an oral dosage forms in its hydrochloride salt form (Fig. 1). This chemical property shows that metformin has low lipophilic property and therefore, the diffusion of metformin through cell membrane is low. After oral administration, metformin is largely absorbed from the upper small intestine, and it undergoes limited systemic absorption with a half-life of about 3 hours. Therefore, repeated administration of the conventional metformin hydrochloride tablets is mandatory for effective treatment. ${ }^{10-12}$

According to Biopharmaceutical Classification System (BCS), metformin is classified under class III drugs. ${ }^{13}$ For such drugs, permeability is the rate-limiting step for drug absorption. Rapid dissolution is especially desirable to maximize the contact time between the dissolved drug and mucosal membrane. So that, the duration of dissolution should be strict. Hence, as drug permeation is rate-limiting, no in-vitro in-vivo correlation (IVIV) is expected. ${ }^{14,15}$

Pharmaceutical products containing the same active ingredient can be produced and marketed by many companies under different 'brand' name as a generic drug products once the patent for the innovator get expired. Generic and innovator products should be the same with respect to quality, safety, efficacy, strength, dosage form, route of administration and intended use. ${ }^{16-18}$ The introduction of generic drugs from multiple sources into the markets improved availability and access to life-saving drug especially in developing countries. ${ }^{19}$ In addition, these generic drugs are marketed with lower price and related with public health cost reduction. ${ }^{20,21}$ Despite these benefits, generic products are also related with variety of problems which might place the customers' health at risk. The interchangeability of generic drugs with the originator might still be questionable.

Quality is one of the most important criteria in guarantying optimal treatment out come from medicines and is presently receiving increased attention in generic manufacturing. ${ }^{22}$ Circulation of poor quality drug products in the international market increased significantly as a result of ineffective regulation of manufacturing and trading of pharmaceutical products. ${ }^{23}$ Therefore, the manufacturing, distribution, storage and use of drugs need to be regulated by authorized regulatory institutions.

Poor quality medicines are public health problems and affect both developing and developed countries. ${ }^{24,25}$ The World Health Organization reported that $10 \%$ medical products in low and middle-income countries are either substandard or falsified ${ }^{26}$ and Ethiopia is one of the low-income countries. Considering this, falsified or substandard medicines could be available in the drug market. Reasons for the supply of such drugs in low and middle income country could be attributed to weak regulatory enforcement, lack of informal market control, weak port control, poor cooperation between executive bodies and resource constraint. ${ }^{27,28}$ The availability of such types of drugs on the market might leads to treatment failure, increased mortality and morbidity, drug resistance and economic loss. ${ }^{29}$ 
For better health of the public, supplying good quality medicine is mandatory. But it is often missing in developing country like Ethiopia which has week regulatory system for pharmaceuticals. World Health Organization (WHO) has estimated that about $30 \%$ of the medicines on sale in Africa countries and parts of Asia and Latin America are counterfeit, while other developing countries have $<10 \%$; overall, a reasonable range is between $10-30 \% .{ }^{30}$ In 2013 , the Public Health and Drug Testing Laboratory (PHDTL) tests 5000 drug samples from Bangladesh's mammoth Pharmaceutical industry and according to this study, $60 \%$ of drugs are either counterfeit or of very poor quality. ${ }^{31}$

Generally, medicines used in health care need certain types of standards to have quality, safety and efficacy. So, monitoring drug quality through in-vitro test is mandatory to safeguard the health of the public as a whole and to reduce morbidity and mortality associated with poor quality medicines. ${ }^{32}$ In Ethiopia, there are very few pharmaceutical manufacturing companies and the country is principally dependant on imported pharmaceuticals. There are many multisource metformin hydrochloride tablets that are legally registered by Ethiopian food and drug administration and available on market for public use. Hence, there should be a means to determine that generic pharmaceutical products are therapeutically equivalent and interchangeable with their innovator's as unpredictable clinical responses have been reported from similar drug products manufactured by different companies. ${ }^{33,34}$ Therefore, this study was conducted to assess the in vitro equivalency of different brands of Metformin hydrochloride $500 \mathrm{mg}$ tablet which are commonly available in drug retail outlet and hospital pharmacies in Jimma town and indiscriminately used in the treatment of diabetic patients. Six different brands of metformin hydrochloride 500 $\mathrm{mg}$ tablets that are available in jimma town were tested and compared for different physicochemical quality parameters including weight variation, friability, dissolution and assay.

\section{Material And Methods}

\section{Study setting and period}

The study was conducted on six brands of metformin hydrochloride tablets available in Jimma town. Jimma town is located $357 \mathrm{~km}$ southwest of Addis Ababa, the capital of Ethiopia and had 17 kebeles with a population of 120,960 and 32,192 households. ${ }^{35}$ The laboratory work was conducted in Jimma University Laboratory of Drug Quality (JuLaDQ). All the brands included in the study where within their shelf life at the time of the study. The laboratory work was done from April-June 2019.

\section{Instruments}

Analytical Balance (Mettler Toledo, Switzerland), RC-6D Dissolution Apparatus (Apparatus 2; Tian Jin Optical Instruments, China), UV-Vis Spectrophotometer (Cecil Instruments, United Kingdom), Friability Tester (Pharma Test), PH meter (AD 1020 PH /MV/ISE), and Water Purification System (Thermo Scientific, Model-7143, Waltham, MA, USA) were used for the study.

\section{Chemical and reagents}

Distilled water, sodium hydroxide (BDG Laboratory Supplies, Purity $=97.5 \%$ ), potassium dihydrogen orthophosphate (Techno Pharm Chem, Bahadurgarh, Purity $=99-101 \%$, India) were used. The working standard of metformin hydrochloride was donated by the Ethiopian Food and Drug Administration Authority (EFDA).

\section{Sampling technique and sample collection}

Before the actual sample collection, we conducted market surveillance and identified that five imported and one locally produced metformin hydrochloride 500 $\mathrm{mg}$ tablets are marketed in Jimma town. All available six brands were purchased from drug retail outlets and hospital pharmacies by mystery shoppers who were trained and blinded about the purpose of the study. The mystery shoppers were told to approach the pharmacist/druggist working in the retail outlets and hospital pharmacies by stating that they are travelers and who has been taking metformin for their diabetic condition and now running out of medication. Guidelines to Conduct Surveys of the Quality of Medicines by Newton were used for sampling strategy. ${ }^{36}$ After collection, all samples were subjected to visual inspection and their manufacturing license number, batch number, manufacturing, and expiry dates, country of origin, batch/lot number were recorded immediately. The samples were kept in their original package, transported to Jimma University laboratory of drug quality (JuLaDQ), and stored under storage condition specified on the label of each product until the analysis. Detail information of the samples was presented in Table 1.

Table 1

Detail information of metformin hydrochloride tablet brands included in the study

\begin{tabular}{|llllll|}
\hline Brands & Manufacturer & Country & Batch number & Man. Date & Exp. Date \\
\hline Glucophage & Merch serono & France & F0582 & $10 / 2018$ & $09 / 2023$ \\
\hline Metformin denk & Denk pharma & Germany & 9 N6 & $07 / 2018$ & $06 / 2023$ \\
\hline Insumet & Cadila Pharmaceuticals PLC & Ethiopia & D18076T212 & $12 / 2018$ & $09 / 2021$ \\
\hline Brot & Medochemie Ltd;Limassol & Cyprus & A1H115 & $08 / 2018$ & $08 / 2022$ \\
\hline Etform & Lek SA,Styrykow;Sandoz anovartis company & Poland & JC2413 & $06 / 2018$ & $06 / 2021$ \\
\hline Metformin & Ningho Shuangwei Pharm.co.Ltd. & China & 180719 & $07 / 2018$ & $07 / 2021$ \\
\hline
\end{tabular}


All samples were visually inspected for their Physical characteristics (shapes, color, breaks, cracks and splits), packaging and labeling information (name of the active pharmaceutical ingredient, the country of origin, manufacturing company, manufacturing date, expiry date, batch/lot number, number of units per strip/package and labeled dose (strength) of the active ingredient) using the modified World health organization (WHO) checklist designed to health professionals to carry out visual inspection of medicines for signs of counterfeiting and report to appropriate national authority or directly to WHO. ${ }^{37}$

\section{Weight variation}

The weight variation test for metformin hydrochloride tablet brands was evaluated according to the method given in USP. ${ }^{38}$ Randomly selected twenty tablets from each brand were weighed individually with calibrated analytical balance and the average weight for each brand was determined. The percentage deviation was calculated from the average weight of the tablets using Eq. 1 and compared against the USP limits for tablet weighing 250 mg or more (i.e.; No more than 2 individual tablet weight deviate by $>5 \%$ of the average tablet weight and none deviating by more than $10 \%$ of the average tablet weight).

$$
\text { percentage deviation }=\frac{(\text { weight of } \text { individual tablet }- \text { Average weight of tablet }) X 100}{\text { Average weight of tablet } !} \ldots \ldots \ldots \ldots \ldots . . . . . .1
$$

\section{Friability Test}

Friability test for metformin hydrochloride tablet brands was evaluated according to the method outlined in USP. ${ }^{38}$ Randomly selected twenty tablets from each brand were weighed and subjected to abrasion using the drum of friability tester at 100 revolutions for 4 min. Then, the tablets were removed from the drum, dedusted and weighed again. Then, percentage weight loss was calculated using Eq. 2, compared against USP criteria for compressed tablets and considered as friability. According to USP criteria, percentage weights lose not more than $1 \%$ is considered to be acceptable and if cracked, cleaved, or broken tablets are present within the tablet sample after tumbling, the tablet fails the test.

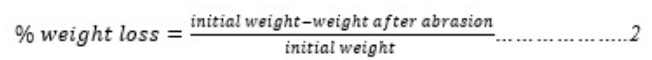

\section{Assay}

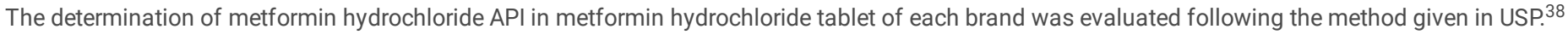

\section{Standard solution preparation}

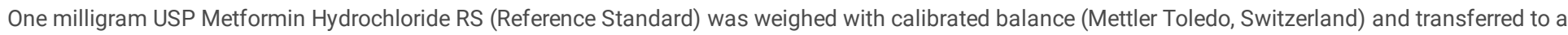
$100 \mathrm{ml}$ volumetric flask. Then $50 \mathrm{ml}$ of water was added, shaked for five minutes and diluted to volume with the same solvent

Sample solution preparation: - The sample solution for metformin hydrochloride tablet brands was prepared by randomly selecting and powdering twenty tablets from each brand using mortar and pestle. Powder weight equivalent to $100 \mathrm{mg}$ of metformin hydrochloride was weighed and transferred to $100 \mathrm{~mL}$ volumetric flask. Then, $70 \mathrm{~mL}$ of water was added, shaked by mechanical means for 15 minutes, diluted with water to volume and filtered. Then, $20 \mathrm{~mL}$ of the first filtrate was discarded after which $10 \mathrm{~mL}$ of the filtrate was taken and diluted with water to $100 \mathrm{~mL}$. Finally, $10 \mathrm{~mL}$ of the resulting solution was taken and further diluted with water to $100 \mathrm{~mL}$ and the absorbance of the resulting solution and standard preparation was measured using Ultraviolet visible spectrophotometer at wavelength of $232 \mathrm{~nm}$ using water as a blank. The quantity, in milligram, metformin hydrochloride in the portion of tablet taken for assay was calculated using Eq. 3 and compared with USP acceptance limit (\%label claim: 95\%- 105\%).

Quantity $(\mathrm{mg})=10 C \frac{A u}{A s} \ldots \ldots \ldots \ldots \ldots(3)$

Where $\mathrm{C}$ is the concentration, in $\mathrm{mg} / \mathrm{mL}$, of USP Metformin hydrochloride RS in the standard preparation, $A u$ and $A s$ are Metformin hydrochloride peak responses obtained from the assay preparation and the standard preparation respectively.

\section{Dissolution test}

\section{Calibration curve construction}

Hundred (100 mg) of USP metformin hydrochloride RS was dissolved in $100 \mathrm{~mL}$ of phosphate buffer to prepare stock solution having $1 \mathrm{mg} / \mathrm{ml}$ concentration. From the stock solution, five concentration levels $(6,7,8,9$ and $10 \mu \mathrm{g} / \mathrm{mL})$ were prepared using the same phosphate buffer as a diluent. Then, absorbance of these concentrations was determined spectrophotometrically at a wavelength of $233 \mathrm{~nm}$ and plotted against the five concentration levels to obtain the calibration curve.

\section{Dissolution profile}

The dissolution profile for metformin hydrochloride tablet was evaluated following the method given in USP. ${ }^{38}$ The dissolution study was carried out using the USP Apparatus II (paddle). The dissolution medium (1000 mL phosphate buffer) was transferred to vessels of dissolution apparatus and maintained at temperature of $37^{\circ} \mathrm{C} \pm 0.5^{\circ} \mathrm{C}$ and paddle rotation of $100 \mathrm{rpm}$. Randomly selected metformin hydrochloride tablets $(n=6)$ from each brand were assigned to the six dissolution vessels. According to USP 2015 specification, at a single point time of 30 minutes, at least $80 \%$ of the drug needs to be released. However, to study the dissolution profile of the drug, $10 \mathrm{ml}$ sample of dissolution medium containing metformin hydrochloride was withdrawn at predetermined time points $(5,15,30$, and $45 \mathrm{~min})$ and replenished with an equal volume of fresh dissolution medium maintained at the same temperature. The withdrawn sample was filtered and diluted (100x). Then, their absorbance was measured by ultraviolet-visible spectrophotometer at a wavelength of $233 \mathrm{~nm}$ using phosphate 
buffer as a blank. The concentration was calculated by using the calibration curve equation generated from a known concentration of Metformin hydrochloride RS and the percentage drug release was calculated at each time point.

\section{Statistical analysis}

For statistical analysis, Microsoft excels 2010 and statistical package for social science were used and $p<0.05$ were used as a cut point for significance. Percentage label claim, weight variation and dissolution profile of different brands were compared by one way analysis of variance (ANOVA). The dissolution profiles of the brands were also compared by the model independent method of fit factors approach and dissolution efficiency (DE). The fit factor approach includes the difference factor $\left(f_{1}\right)$ and the similarity factor $\left(f_{2}\right) \cdot{ }^{39} D E$ is the area under the dissolution curve between defined time points. ${ }^{40}$

\section{Results}

Among the six different brands of metformin hydrochloride tablets evaluated, one brand was locally produced in Ethiopia, while the remaining five brands were imported from abroad. Both official and non-official tests were done to evaluate the quality of the different brands of metformin hydrochloride tablets. Official tests like Weight variation, dissolution test and drug content analysis (assay) and the non-official test; friability test were evaluated according to the method outlined in USP. One of the non- official test hardness was not performed. This is because hardness test is mainly done to determine the need for pressure adjustment on the tableting machine during production and by itself it is not quality determinant.

\section{Physical characteristics, packaging and labeling}

The physical characteristics, packaging and labeling result showed that all the tested brands had a uniform white color, undamaged, and did not had any odor. Except for Insumet, all metformin hydrochloride tablets had a circular shape. But, Insumet had an oval shape. The packaging and labeling of all brands meet the minimum requirement required by the World Health Organization for packaging and labeling (The result for physical characteristics, packaging, and labeling was presented in the supplementary file 1.

\section{Weight variation and friability}

The weight variation and friability test result of metformin hydrochloride tablet were depicted in Table 2. Brot and Etform had the highest and lowest mean weight respectively. Except for insumet, all the brands passed the weight variation test as none of them had percentage deviation greater than $5 \%$ from the mean tablet weight as specified in USP. Statistical analysis using One-way ANOVA at $95 \%$ confidence interval $(\mathrm{Cl})$ showed significant differences $(p<0.001)$ among samples mean weight of all brands. Furthermore, Dennett multiple comparisons test performed to identify the source of difference between the test products and the comparator revealed that there was a mean tablet weight difference between the compactor and all tested products (Table 3 ). In this study, the percentage friability of the tested brands ranged from $0-7.37 \%$. Metformin denk and Etform did not lose their content after the friability test. Except for Brot, all the brands passed the friability test according to the USP limit, which states percentage weight lose not more than $1 \%$ is considered to be acceptable.

Table 2

Physicochemical characteristics (weight variation, friability and assay test) of metformin hydrochloride tablets tested.

\begin{tabular}{|c|c|c|c|c|c|c|c|}
\hline Brands & Weight variation (mean \pm std. error) & UB & LB & P-value & Friability (\%) & Assay \% (mean \pm SD; $n=3)$ & p-value \\
\hline Glucophage $^{*}$ & $532.08 \pm 0.91$ & 533.99 & 589.07 & \multirow[t]{6}{*}{$P<0.001$} & 0.014 & $96.46 \pm 0.03$ & \multirow[t]{6}{*}{$P<0.001$} \\
\hline Metformin denk & $656.87 \pm 1.19$ & 659.35 & 654.39 & & - & $95.21 \pm 0.14$ & \\
\hline Insumet & $660.72 \pm 1.36$ & 663.58 & 657.86 & & 0.0197 & $99.61 \pm 0.03$ & \\
\hline Brot & $677.14 \pm 0.87$ & 678.97 & 675.30 & & $7.37 * 10^{-4}$ & $95.41 \pm 0.03$ & \\
\hline Etform & $524.51 \pm 0.82$ & 526.22 & 522.80 & & - & $98.28 \pm 0.02$ & \\
\hline Metformin & $554.26 \pm 3.54$ & 561.68 & 546.84 & & 0.055 & $96.12 \pm 0.02$ & \\
\hline
\end{tabular}

Table 3

-Dennett multiple comparisons test for uniformity of weight of metformin hydrochloride tablets tested with innovator

\begin{tabular}{|lllllll|}
\hline Tested brands & Innovator & Mean difference (tested-innovator) & Std. Error & Sig. & \multicolumn{2}{l|}{ 95\% Confidence Interval } \\
\cline { 6 - 8 } & & & & & Lower Bound & Upper Bound \\
\hline Insumet & Glucophage & 128.64 & 2.46 & $<0.001$ & 122.38 & 134.89 \\
\hline Metformin denk & Glucophage & 124.79 & 2.46 & $<0.001$ & 118.53 & 131.04 \\
\hline Etform & Glucophage & -7.58 & 2.46 & $<0.001$ & -13.83 & -1.32 \\
\hline Metformin & Glucophage & 22.18 & 2.46 & $<0.001$ & 15.92 & 28.43 \\
\hline Metformin & Glucophage & 145.05 & 2.46 & $<0.001$ & 138.79 & 151.31 \\
\hline Brot & Glucophage & 128.64 & 2.46 & $<0.001$ & 122.38 & 134.89 \\
\hline
\end{tabular}


The result for the Ultraviolet visible spectrophotometer assay of the different brands of Metformin hydrochloride tablet is depicted in Table 2. With regard to the Metformin hydrochloride content in the tablet dosage forms analyzed, all the brands complied with the acceptance specification set in USP, (i.e. \% label claim: 95\% -105\%). The Metformin hydrochloride content in Metformin hydrochloride tablet dosage forms ranged from 95.21-99.61\%, with Insumet and metformin denk respectively. The statistical analysis using One-way ANOVA at $95 \% \mathrm{Cl}$ showed that there was significant difference in drug content among the different brands of metformin hydrochloride tablet (Table 2). Additionally, post hoc Dennett multiple comparisons test performed to spot out the source of difference between the test products and the comparator in terms of their drug content revealed that there was a drug content difference between the compactor and all tested products (Table 4).

Table 4

Dennett multiple comparisons test for assay of metformin hydrochloride tablets tested with innovator

\begin{tabular}{|lllllll|}
\hline Tested brands & Innovator & Mean Difference (tested-comparator) & Std. Error & Sig. & \multicolumn{2}{c|}{$\mathbf{9 5 \%}$ Confidence Interval } \\
\cline { 5 - 8 } & & & & & Lower Bound & Upper Bound \\
\hline Insumet & Glucophage & 3.15 & 0.05 & $<0.001$ & 3.01 & 3.29 \\
\hline Metformin denk & Glucophage & -1.25 & 0.05 & $<0.001$ & -1.39 & -1.11 \\
\hline Etform & Glucophage & 1.82 & 0.05 & $<0.001$ & 1.68 & 1.96 \\
\hline Metformin & Glucophage & -0.34 & 0.05 & $<0.001$ & -0.48 & -0.20 \\
\hline Brot & Glucophage & -1.05 & 0.05 & $<0.001$ & -1.19 & -0.91 \\
\hline
\end{tabular}

\section{Calibration curve for dissolution study}

The calibration curve for the applied UV-visible spectroscopic method in the determination of amount of Metformin hydrochloride released is shown in Fig. 2. The result from the calibration curved revealed the presence of strong positive relationship $\left(r^{2}=0.9986\right)$ between the concentration and absorbance over the concentration range of 6 to $10 \mu \mathrm{g} / \mathrm{ml}$.

\section{Dissolution Study}

The dissolution profile of tested brands of metformin hydrochloride tablet is indicated in Fig. $\mathbf{3}$ and a single point dissolution test result at pharmacopoeial specified time of 30 minute is shown in Table 5. The dissolution result indicates that all the tested brands released more than $80 \%$ of the labeled amount within the specified time point showing compliance to USP pharmacopoeial specification for dissolution of metformin hydrochloride table dosage form. The release rate of the drug ranged from $85.4 \%$ for Metformin denk to $96.7 \%$ for Etform. The result of one-way ANOVA statistical analysis conducted at $95 \% \mathrm{Cl}$ revealed that there was no s significant difference in the release of Metformin hydrochloride from the drug matrices among the tested brands and the comparator product (Table 5). In order to assess the interchangeability, the model independent method ( $f 1$ and $f 2)$ were done and the result showed that Metformin denk, Insumet, and Brot had a similarity factor $\left(f_{2}\right)$ of greater than $50 \%$, and all the brands had a difference factor $\left(f_{1}\right)$ of less than 15 (Table 5$)$. All the brands had a difference in dissolution efficiency of within $\pm 10 \%$.

Table 5

Single point

$(\mathrm{t}=30 \mathrm{~min})$

dissolution

test result for

metformin

hydrochloride

tablets tested

\begin{tabular}{|c|c|c|c|c|c|c|}
\hline \multirow[t]{2}{*}{ Brands } & \multirow[t]{2}{*}{ Dissolution at 30 minutes } & \multirow[t]{2}{*}{ p-value } & \multicolumn{2}{|c|}{ Model independent approach } & \multirow[t]{2}{*}{$\mathrm{DE}(\%)$} & \multirow[t]{2}{*}{ Difference of dissolution efficiency (\%) } \\
\hline & & & $f_{1}$ & $f_{2}$ & & \\
\hline Glucophage & 94.7 & \multirow[t]{6}{*}{0.91} & - & - & 72.65 & - \\
\hline Metformin denk & 85.4 & & 9.29 & 86.32 & 66.84 & 5.81 \\
\hline Insumet & 87.4 & & 7.33 & 53.80 & 65.22 & 7.43 \\
\hline Brot & 87.1 & & 7.58 & 57.45 & 71.83 & 0.82 \\
\hline Etform & 96.7 & & 1.96 & 3.83 & 75.54 & -2.89 \\
\hline Metformin & 89.1 & & 5.77 & 33.29 & 75.99 & -3.34 \\
\hline
\end{tabular}

To augment the one-way ANOVA, the Dunnett multiple comparisons test were conducted at $95 \% \mathrm{Cl}$ with the comparator/innovator and the result indicates that there was no statistically significant difference in the release profile between comparator and tested brands (Table 6). 
Table 6

Dunnett multiple comparisons test for dissolution study of metformin hydrochloride tablets tested with the innovator

\begin{tabular}{|llllllll|}
\hline Tested brands & Innovator & Mean Difference (tested-comparator) & Std. Error & Sig. & \multicolumn{2}{c|}{$95 \%$ Confidence Interval } \\
\cline { 5 - 8 } & & & & & Lower Bound & Upper Bound \\
\hline Insumet & Glucophage & -5.13 & 21.73 & .999 & -65.14 & 54.8692 \\
\hline Metformin denk & Glucophage & -13.99 & 21.73 & .948 & -74.00 & 46.0061 \\
\hline Etform & Glucophage & -13.99 & 21.73 & .948 & -74.00 & 46.0061 \\
\hline Metformin & Glucophage & 7.15 & 21.73 & .997 & -52.85 & 67.16 \\
\hline Brot & Glucophage & -2.14 & 21.73 & 1.000 & -62.14 & 57.86 \\
\hline
\end{tabular}

\section{Discussion}

According to the present study, all the tested brands had a uniform white color, undamaged, and did not have any odor. All the tested brands had a circular shape except Insumet which had an oval shape. The results for visual inspection of physical characteristics, packaging and labeling did not show any signs of spurious, falsely labeled, falsified or counterfeit products as defined by the WHO. No defect in physical characteristic of the tables was observed and there was also no incorrect, inadequate or incomplete labeling of metformin hydrochloride tablet brands that leads to suspicion of the product for potential counterfeit. ${ }^{37}$ weight variation test was used to check if the tablets have uniform content or not. So, batch/s has active pharmaceutical ingredient/s within a narrow range round the label claim. ${ }^{38}$ Dosage unit was dosage form containing a unit dose or a part of a dose of drug substance in each unit.

According to this study, only Insumet has failed the weight variation test by having a percent mean deviation of more than 10 . Weight variation test failure of Insumet may cause the unavailability of the necessary amount of active pharmaceutical ingredient required for therapeutic effect in the unit dose; this might intern leads to a reduction in the therapeutic activity of the drug and cause a reduced patient outcome. Furthermore, statistical analysis revealed that there were significant differences $(p<0.001)$ between the samples mean weights of all brands. This weight variation might be due to the difference in the types of excipients like diluent, disintegrant, lubricant, and glidants used during the manufacturing process. This difference might also associate to differences in manufacturing process. A study conducted in India on four different brands of metformin hydrochloride tablets showed that the entire tablets were passed the test for weight variation and friability. ${ }^{41}$ From eight metformin HCL tablet brands tested in Nigeria, all the brands were also passed the test for weight variation, and one of the brands was failed to pass the test for friability. ${ }^{42} \mathrm{~A}$ similar result was also reported from India in 2012 in which all the tested brands were passed the weight variation and friability test. ${ }^{43}$ However, according to this study, Insumet failed the official test of weight variation. The discrepancy may be attributed to the types of brands included in the study, difference in personnel qualifications and the standard of laboratory.

The assay test is an important test used to quantify the amount of active ingredients present in the product. The amount of active ingredient present in one product affects the quality and will have an impact on the therapeutic effect. The drug which does not have the required active pharmaceutical ingredient cannot produce the necessary therapeutic outcome, and might leads to treatment failure, morbidity, and mortality to patients. According to this study, all metformin hydrochloride tablet brands were within their specifications and satisfied the assay requirement of USP 2015 (95-105\% Ic). The finding was similar to the reports from Tigray. ${ }^{44}$ Sri Lanka ${ }^{45}$ and India ${ }^{46}$, but, different from study done in Nigeria. ${ }^{42}$ This difference might be due to differences in the drug regulation system of different countries and differences in types of brands included in the study.

In vitro dissolution study from oral solid dosage forms is an important precondition for drug bioavailability and can be used as an alternative approach for bioequivalence studies that can forecast therapeutic equivalence between reference and test products which are pharmaceutical equivalent. ${ }^{47}$ Dissolution test result of tablets may indicate the impact of ingredients included in the formulation on the in vivo performance of the drug. According to this study, all the brands passed a single-point dissolution study and complied with USP specification by releasing more than $80 \%$ in 30 minutes. However, metformin hydrochloride, a BCS class III drug fails to release more than $85 \%$ within 15 minutes and not eligible for biowaiver. This might be due to either the excipients used or due to the $\mathrm{PH}$ of the dissolution medium used. The dissolution result was similar to the report from India ${ }^{43}$ and different from a study done in Addis Ababa, Ethiopia. ${ }^{48}$ This difference in dissolution might be due to the inclusion of different brands for the study.

Statistically, there were no significant differences in the release of the drug substance from metformin hydrochloride tablet matrices of the brands ( $p>0.05$ ). To support the one-way ANOVA, Dunnet multiple comparisons test was also performed at $95 \% \mathrm{Cl}$ between the innovator and tested brands and revealed that there was no statistically significant difference in the release profile between comparator and tested brands. In addition, the interchangeability/equivalency of tested brands and innovator was evaluated by fit factors. Fit factors include similarity $\left(f_{2}\right)$, and the difference $\left(f_{1}\right)$ factors. For the test drugs to be used interchangeably with the innovator, the similarity factor $\left(f_{2}\right)$ should be $50-100$, and the difference factor $\left(f_{1}\right)$ should be $1-15 .{ }^{39}$ According to the above acceptance criteria, Insumet, Metformin denk, and Brot had $f_{2}$ value of $>50$ and $f_{1}$ value of $<15$ and were equivalent with the innovator drug Glucophage. On the other hand, Etform and Metformin had $\mathrm{f}_{2}<50$ and failed to be bioequivalent with the innovator drug Glucophage. Furthermore, to ensure the interchangeability of such drugs with the innovator drug, the release profile was compared by calculating the dissolution efficiency for the different brands of metformin hydrochloride tablets included in the study. The test product is interchangeable/equivalent with the innovator if and only if the difference between their dissolution efficiency (innovator drug-test drug/vice versa) is within $\pm 10 \% .{ }^{40}$ Based on this requirement all brands of metformin hydrochloride tablets were equivalent to the innovator product as the difference in dissolution efficiency is $<10 \%$. 


\section{Conclusion}

This study tried to analyze the quality as well as the physicochemical equivalency of six brands of metformin hydrochloride tables available in Jimma town. All the tested brands were in line with the World Health Organization guideline for evaluation of packaging and labelling of pharmaceuticals for the sign of counterfeit. The physicochemical evaluation revealed that all brands met the USP quality specification for friability, dissolution and assay. However, one brand (Insumet) failed to comply with the United States Pharmacopeia specification for uniformity of weight. Statistically, all the brands had a significant difference in their mean weight and mean assay value from the innovator $(p<0.05)$. The dissolution profile comparison has established the interchangeability of the tested products with the comparator drug.

\section{Declarations}

\section{Ethical approval:}

Not applicable

\section{Consent for publication}

Not applicable

\section{Data Availability}

All necessary data are available within the manuscript and if required, raw data like chromatograms will be available from the corresponding author up on request

\section{Competing interest}

The authors declare that they have no competing interest.

\section{Funding}

This study was funded by the Students Research Project (SRP) of Jimma University

\section{Authors' contribution}

YM designed and coordinated the study, along with AB. BU collected the samples and drafted the manuscript. SS performed the data analysis. All authors read and approved the final manuscript.

\section{Acknowledgement}

The authors would like to acknowledge Jimma University for providing financial aid to this research. The authors are also grateful to Ethiopian food and drug administration (EFDA) for the kind donation of the working standard of metformin hydrochloride.

\section{References}

1. Faten M. R. Ismael N.A. A. Diabetic patients knowledge, attitude and practice toward oral health. JEP. 2013; 4 (20):19-25. https://core.ac.uk/download/pdf/234634762.pdf

2. Boruah P, Chakraborty J, Dash S. A comparative evaluation of antidiabetic potentiality found in different marketed polyherbal formulation using glucocorticoid-induced hyperglycaemia in rabbit. Int J Curr Pharm Res. 2017; 9 (4):83-85. https://doi.org/10.22159/ijcpr.2017v9i4.20964

3. Prithi IJ, Chowdhury SF, Chowdhury ST. Comparative in vitro dissolution test and other physicochemical parameters of some commercially available metformin $\mathrm{HCl}$ brands in Bangladesh. Pharma Innov. 2018; 7:5-8.

4. Tripathi BK, Srivastava AK. Diabetes mellitus: complications and therapeutics. Med Sci Monit. 2006;12 (7): RA130-47. https://pubmed.ncbi.nlm.nih.gov/16810145/

5. Chen L, Magliano DJ, Zimmet PZ. The worldwide epidemiology of type 2 diabetes mellitus-present and future perspectives. Nat Rev Endocrinol. 2011; 8 (4): 228-236. https://doi.org/10.1038/nrendo.2011.183

6. Graham, G.G., Punt, J., Arora, M. et al. Clinical pharmacokinetics of metformin. Clin pharmacoknet. 2011; 50 (2); $81-89$. https://doi.org/10.2165/11534750-000000000-00000

7. Hughes RC, Gardiner SJ, Begg EJ, Zhang M. Effect of pregnancy on the pharmacokinetics of metformin. Diabet Med. 2006; 23(3):323-6. https://doi.org/10.1111/j.1464-5491.2005.01769.x

8. Kabir, A., Jeseem, T., Jahangir, R., Rahman, D., \& Rouf, A.Formulation development and in vitro evaluation of metformin hydrochloride matrix tablets based on hydroxypropyl methyl cellulose. Stamford J Pharm Sci. 2008; 1(1):51-6. https://doi.org/3329/sjps.v1i1.1808

9. Petrovick GF. Type 2 diabetes mellitus and metformin hydrochloride usage: a short review. Pharmacol Ther Res. 2018; 2(2):6-9. https://www.alliedacademies.org/articles/type-2-diabetes-mellitus-and-metformin-hydrochloride-usage-a-short-review.pdf

10. Sachan AK, Kumar V, Gupta A. Comparative in-vitro evaluation of four different brands of metformin HCl available in Kanpur district, India. Pharm Lett. 2016; 8 (5):419-424. https://www.scholarsresearchlibrary.com/articles/comparative-invitro-evaluation-of-four-different-brands-of-metformin-hclavailable- 
in-kanpur-district-india.pdf

11. Garza-OL, Gonzalez-CJ, Tamez OE, et al. Comparative Bioavailability of Metformin Hydrochloride Oral Solution Versus Metformin Hydrochloride Tablets in Fasting Mexican Healthy Volunteers. Adv Ther. 2019; 36 (2):407-415. https://doi.org/10.1007/s12325-018-0853-3

12. Mokhtare B, Cetin M, Ozakar RS, Bayrakceken $\mathrm{H}$. In vitro and in vivo evaluation of alginate and alginate-chitosan beads containing metformin hydrochloride. Trop J Pharm Res. 2017; 16 (2):287-296. https://doi.org/4314/tjpr.v16i2.5

13. Patel A, Ray S, Thakur Rams. Invitro evaluation and optimization of controlled release floating drug delivery system of metformin hydrochloride. Daru. 2006; 14(2):57-64.

14. Emami J. In vitro - In vivo Correlation: From Theory to Applications. J Pharm Pharm Sci. 2006; 9(2):169-89.

15. Amidon GL, Lennernäs H, Shah VP, Crison JR. A theoretical basis for a biopharmaceutic drug classification: the correlation of in vitro drug product dissolution and in vivo bioavailability. Pharm Res. 1995; 12(3):413-420. https://doi.org/10.1023/a:1016212804288

16. World Health Organization (WHO). Glossary of Globalization, Trade and Health Terms. 2012; Available from: http://www.who.int/ trade/glossary/story034/en/index.html. Accessed on Sebtember , 2020

17. Davit BM, Nwakama PE, Buehler GJ, et al. Comparing generic and innovator drugs: a review of 12 years of bioequivalence data from the United States Food and Drug Administration. Ann Pharmacother. 2009;43 (10):1583-1597. https://doi.org/10.1345/aph.1M141

18. Cameron A, Mantel-Teeuwisse AK, Leufkens HG, Laing RO. Switching from originator brand medicines to generic equivalents in selected developing countries: how much could be saved?. Value Health. 2012;15(5):664-673. https://doi.org/10.1016/j.jval.2012.04.004

19. Osman Z, Osman AE, Abedelghayoum AM. Comparative evaluation of physicochemical properties of some commercially available brands of metformin $\mathrm{HCl}$ tablets marketed in Sudan. Indo Am. j. pharm.2017; 7:7471 -7477. https://zenodo.org/record/1007055

20. Hanafy AF. In-vitro bioequivalence, physicochemical and economic benefits study for marketed innovator and generic ciprofloxacin hydrochloride tablets in Saudi Arabia. J Appl Pharm Sci. 2016;6:63-68. https://doi.org/10.7324/JAPS.2016.60909

21. Del Tacca M, Pasqualetti G, Di Paolo A, et al. Lack of pharmacokinetic bioequivalence between generic and branded amoxicillin formulations. A postmarketing clinical study on healthy volunteers. Br J Clin Pharmacol. 2009;68 (1):34-42. https://doi.org/10.1111/j.1365-2125.2009.03399.x

22. Alghannam AFA, Aslanpour Z, Evans S, Schifano S. A systematic review of counterfeit and substandard medicines in field quality surveys. Integr Pharm Res Pract. 2014; 3:71 -88.

23. Binega G, Wondimsigegn D, Tsega B. Analysis and Comparison of Paracetamol Tablets Dispenced in Legal Dispenceries and Non Pharmaceutical Shopes in Gonder Town, North West Ethiopia. Int J Pharm Ind Res. 2013;3(2):144-51. https://1library.net/document/z1ej23dy-analysis-comparison-paracetamoltablets-dispensed-dispensaries-pharmaceutical-ethiopia.html

24. Dégardin K, Roggo Y, Margot P. Understanding and Fighting the Medicine Counterfeit Market. J Pharm Biomed Anal. 2014;87:167-75. https://doi.org/10.1016/j.jpba.2013.01.009.

25. Chika A, Bello SO, Jimoh AO, Umar MT. The Menace of Fake Drugs: Consequences, Causes and Possible Solutions. Res J Med Sci. 2011;5(5):257-61. https://doi.org/10.3923/rjmsci.2011.257.261

26. World Health Organization (WHO): Fake Drugs Are A Major Global Problem, WHO Reports. 2017. https://www.who.int/medicines/regulation/ssffc/publications/GSMSreport_EN.pdf?ua=1

27. Kahsay G, Debella A, Asres K. Comparative In Vitro Quality Evaluation of Ciprofloxacin Tablets from Drug Retail Outlets in Addis Ababa, Ethiopia. Ethiop Pharm J. 2007;25:1-8. https://doi.org/4314/epj.v25i1.35109

28. Suleman S, Woliyi A, Woldemichael K, Tushune K, Duchateau L, Degroote A, et al. Pharmaceutical Regulatory Framework in Ethiopia: A Critical Evaluation of Its Legal Basis and Implementation. Ethiop J Heal Sci. 2016;26(3):259-76. https://doi.org/4314/ejhs.v26i3.9

29. Newton PN, Green MD, Fernández FM. Impact of Poor-Quality Medicines in the “Developing” World. Trends Pharmacol Sci. 2010;31:99-101. https://doi.org/10.1016/j.tips.2009.11.005

30. WHO fact sheet. Substandard and falsified medical products.Key facts.2008. https://www.who.int/news-room/fact-sheets/detail/substandard-andfalsified-medical-products

31. Dastgiri A, Siahi M, Tamizi E. A comparative in-vitro study for evaluation of physicochemical properties of the domestic and innovator brands of sertraline hydrochloride tablets available in the Iranian market. Sci.. 2017; 24(4):271-7. https://doi.org/ 10.15171/PS.2017.40

32. Dyade GK, Joshi HA PR.Estimation of metformin hydrochloride and glimepiride in tablet formulations by uv-visible spectrophotometry. Indo AM $J$ Pharm Res. 2013;3(1):1381-1386. https://www.semanticscholar.org/paper/estimation-of-metformin-hydrochloride-and-in-tablet-Ha$\mathrm{Rn} / 3 \mathrm{db} 379 \mathrm{~d} 5 \mathrm{~d} 628 \mathrm{c} 07 \mathrm{ffbf5a} 83 \mathrm{e} 1878701162 \mathrm{bbc334}$

33. Adegbolagun OA, Olalade OA, Osumah SE. Comparative evaluation of the biopharmaceutical and chemical equivalence of some commercially available brands of ciprofloxacin hydrochloride tablets. Trop J Pharm Res. 2007; 6 (3):737-745.https://doi.org/ 4314/tjpr.v6i3.14654

34. Eraga SO, Arhewoh MI, Oruh EP, Iwuagwu MA. A comparative evaluation of the pharmaceutical quality of different brands of metformin hydrochloride tablets available in Abuja, Nigeria. West J. Pharm. 2017; 28:61 -71. https://docplayer.net/174582324-A-comparative-evaluation-of-the-pharmaceuticalquality-of-different-brands-of-metformin-hydrochloride-tablets-available-in-abuja-nigeria.html

35. Berhanu H, Mossie A, Tadesse S, Geleta D. Prevalence and Associated Factors of Sleep Quality among Adults in Jimma Town , Southwest Ethiopia: A Community-Based Cross-Sectional Study. Sleep Disord. 2018; 2018.22. https://doi.org/ $10.1155 / 2018 / 8342328$

36. WHO Expert Committee on Specifications for Pharmaceutical Preparations. Guidelines on the Conduct of Surveys of the Quality of Medicines. WHO Technical Report Series No. 996. 2016. 23 
37. World health organization (WHO). Tool for visual inspection. Geneva, Switzerland. Available: http://www.whpa.org/toolkit_beaware_inspection.pdf

38. US Pharmacopoeia National Formulary, USP 38/NF33, United States Pharmacopoeial Convention. Rockville, MD, USA; 2015

39. Food and Drug Administration, Food and Drug Administration. Guidance for industry: dissolution testing of immediate release solid oral dosage forms. Center for Drug Evaluation and Research (CDER), US Department of Health and Human Services. 1997 Aug.

40. Anderson NH, Bauer M, Boussac N, Khan-Malek R, Munden P, Sardaro M. An evaluation of fit factors and dissolution efficiency for the comparison of in vitro dissolution profiles. J pharm and biomed Anal. 1998 Aug 1; 17(4-5):811-22. https://doi.org/ 10.1016/s0731-7085(98)00011-9

41. Sachan AK, Kumar V, Gupta A. Comparative in-vitro evaluation of four different brands of metformin $\mathrm{HCl}$ available in Kanpur district, India. Der Pharm Lett. 2016; 8(5):419-24.

https://www.researchgate.net/publication/302577723_Comparative_invitro_evaluation_of_four_different_brands_of_metformin_HCl_available_in_Kanpur_

42. Olusola AM, Adekoya Al, Olanrewaju OJ, Olusola AM, Adekoya Al. Comparative Evaluation of Physicochemical Properties of Some Commercially Available Brands of Metformin Hcl Tablets in Lagos, Nigeria. J Appl Pharm Sci. 2012; 02(02):41-4.

https://japsonline.com/admin/php/uploads/377_pdf.pdf

43. Sheorey SD, Hinge MA, Sengupta R, Menon B V. Pharmaceutical Equivalence Between Different Brands of Metformin Hydrochloride Tablets. J Pharm Res. 2012; 5(6):3456-9.

https://www.researchgate.net/publication/285288513_Pharmaceutical_Equivalence_Between_Different_Brands_of_Metformin_Hydrochloride_Tablets

44. Tesfay K, Kahsay G, Sc D. In Vitro Quality Evaluation of Metformin Hydrochloride Tablets Marketed in Western and North Western Tigray. Austin J Anal Pharm Chem. 2019;6(2). http://www.austinpublishinggroup.com/

45. Hettiarachchi T. W., Wickramaratne D. B., Sudeshika S. H., Dakshila M. H. Comparative in-vitro evaluation of metformin HCL and paracetamol tablets commercially available in kandy district, Sri Lanka. Int J Pharm Pharm Sci. 2015; 7(2).

https://www.researchgate.net/publication/299511779_Comparative_in-

vitro_evaluation_of_metformin_hcl_and_paracetamol_tablets_commercially_available_in_Kandy_district_Sri_Lanka

46. Venkateswara Rao, S., Divya, K. and Padmalatha K et al. Original Research Article comparative in vitro studies and bioequivalence assessment of some commercially available metformin hydrochloride tablets in vijayawada. int j dev res. 2017;07(11):16534-40. https://www.journalijdr.com/comparativevitro-studies-and-bioequivalence-assessment-some-commercially-available-metformin

47. Guidelines for Bioavailability \& Bioequivalence Studies, Central Drugs Standard Control Organization (CDSCO), Directorate General of Health Services, Ministry of Health \& Family Welfare, Government of India,

New Delhi [internet]. Available from: https://cdscoonline.gov.in > CDSCO.

48. Kassahun H, Asres K, Ashenef A. In vitro quality evaluation of metformin hydrochloride tablets marketed in Addis Ababa. Bangladesh J Sci Ind Res. 2019 Jun 1; 54(2):169-76. https://doi.org/ 3329/bjsir.v54i2.41674

\section{Figures}

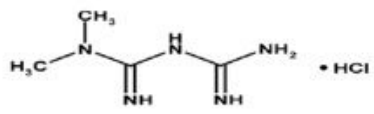

\section{Figure 1}

Chemical structure of metformin hydrochloride

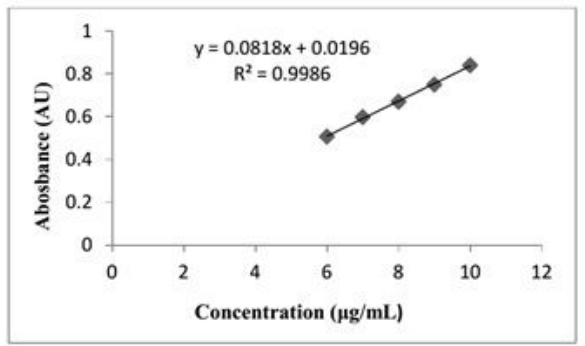

\section{Figure 2}

Calibration curve of Metformin HCL reference standard in phosphate bugger at maximum wave length of $223 \mathrm{~nm}$. 


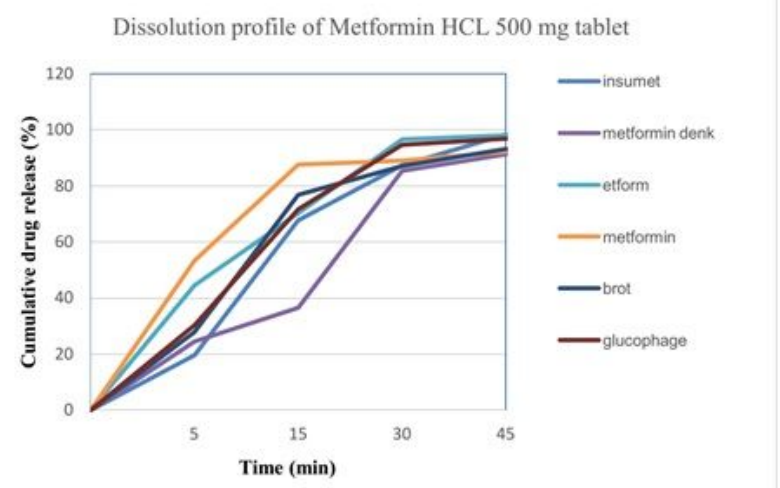

\section{Figure 3}

Dissolution profile (mean $\pm S D, n=6$ ) of Metformin hydrochloride tablet brands in phosphate buffer medium (1000 mL) using USP apparatus II.

\section{Supplementary Files}

This is a list of supplementary files associated with this preprint. Click to download.

- Supplementaryfile.docx 